\title{
Shale Permeability under Shale Components' Thermal Swelling
}

\author{
Xiang Ao $\mathbb{D}^{1,2}$ Jiren Tang, ${ }^{3}$ Hai Qu $\mathbb{D}^{1,2}$ and Zuping Xiang ${ }^{1,2}$ \\ ${ }^{1}$ Chongqing Key Laboratory of Complex Oil and Gas Field Exploration \& Development, Chongqing University of Science \\ and Technology, Chongqing 401331, China \\ ${ }^{2}$ Chongqing Key Laboratory of Heavy Oil Exploitation, Chongqing University of Science and Technology, Chongqing 401331, China \\ ${ }^{3}$ State Key Laboratory for Coal Mine Disaster Dynamics and Control, Chongqing University, Chongqing 400044, China \\ Correspondence should be addressed to Xiang Ao; aoxiang900409@gmail.com and Hai Qu; quhai729@163.com
}

Received 15 March 2021; Revised 6 April 2021; Accepted 17 April 2021; Published 11 May 2021

Academic Editor: Zhengyang Song

Copyright (C) 2021 Xiang Ao et al. This is an open access article distributed under the Creative Commons Attribution License, which permits unrestricted use, distribution, and reproduction in any medium, provided the original work is properly cited.

\begin{abstract}
Permeability is one of the most fundamental reservoir rock properties required for modeling hydrocarbon production. However, shale permeability is not yet fully understood because of the high temperature of shale reservoirs. The third thermal stress that is caused by temperature change will decrease the permeability of shale. In this work, a theoretical model has been derived to describe the permeability of shale considering the third thermal stress; the principles of thermodynamics and the mechanics of elasticity have been employed to develop this model. The elastic modulus parameters of the shale were measured, along with Poisson's ratio, as required. Lastly, the permeability of shale was tested by transient pulse-decay. Isothermal flow experiments were carried out at $303,313,323$, and $333 \mathrm{~K}$ to assess the effects of shale expansion and deformation on shale permeability caused by the third thermal stress. The permeability of shale samples, as predicted by the model, was found to agree well with experimental observations. The model may provide useful descriptions of the gas flow in shale. The correction accuracy of the permeability was found to increase at lower permeability. However, the development of completely predictive models for shale permeability will require additional experimental data and further testing.
\end{abstract}

\section{Introduction}

Shale gas is an unconventional but promising gas resource that has been used with significant success in the world. Permeability is one of the most fundamental properties of any reservoir rock, and it is required for modeling hydrocarbon production. Heller et al. [1] measured the permeability of the Barneet and Eagle Ford shales at low pressure (6.9 MPa) and reported the influence of confining pressure and pore pressure on permeability. Javadpour et al. [2] obtained nanoscale images of shale porosity using an atomic force microscope and then presented a model for gas flow in the nanopores of mudrocks based on the theory of Knudsen diffusion and slip flow. Kwon et al. [3] investigated the effect of effective stress on shale permeability using Wilcox shale. Chalmers et al. [4] measured the permeability of gas shale from the Liard Basin and assessed the effects of origin and distribution, total organic carbon (TOC) content of minerals, porosity, and effective stress on the permeability of the matrix. Mahnaz et al. [5] used helium as a medium to measure the permeability of shale and assessed the Klinkenberg effect on the permeability of gas shale. The permeability of rock change by the wetting-drying cycles and freeze-thawfatigue loading was reported by Song et al. [6, 7].

The thickness of gas shales varies widely. For example, a study of five shale gas systems in the USA indicates a range in shale thicknesses of 2 to $700 \mathrm{~m}$, and the maximum reported thickness of Chinese gas shales is $925 \mathrm{~m}$ [8-10]. Therefore, geothermal differences associated with depth will change the permeability of the shale. Zhang et al. [11] measured the permeability of Carrara marble at different temperatures. They found that marble penetration was significantly increased when the temperature rose to $600-700 \mathrm{~K}$. Li and Xian [12] carried out coal permeability experiments under 
different stress and temperature conditions using methane and helium. Liang et al. [13] measured the permeability of coal samples from Bang Xin $\mathrm{Zu}$. They concluded that there is an exponential relationship between the permeability of coal and the temperature. Feng et al. [14] measured the permeability and deformation of the high-rank coal while increasing the temperature from 298 to $873 \mathrm{~K}$.

Current studies mainly focus on the temperature effects on the permeability of rock. However, temperature effects on the permeability properties of rocks containing complicated components such as shale are comparatively unknown. Thermal stress can be divided into three categories [15]: (1) the first thermal stress, which is produced by the external deformation of homogeneous materials by heating; (2) the second thermal stress, which is produced as a result of the nonuniform temperature distribution within the same object that cannot freely deform; and (3) the third thermal stress, which occurs in materials comprised of multiple components with different linear expansion coefficients that produce thermal stress due to differences in expansion coefficients as the temperature changes. The thermal stress produced in a shale under the impacts of temperature generally consists of the third thermal stress. The reason for this is that shale accumulations in China are generally composed of organic matter and minerals (quartz, calcite, and clay minerals), and the linear expansion coefficients of these minerals do not have the same magnitude $[16,17]$.

In this paper, a model is proposed that is based on the principles of thermodynamics and mechanics of elasticity, to describe the temperature impacts of shale permeability under the third thermal stress conditions. The correction factor is tested by experimental measurements on the permeability of shale at $303,313,323$, and $333 \mathrm{~K}$.

\section{Model}

2.1. Calculation of the Third Thermal Stress. Since shale is composed of different mineral components, the linear expansion coefficient of shale $\alpha$ is calculated considering the linear expansion coefficients of the constituent minerals and organic matter:

$$
\alpha=\sum v_{i} \alpha_{i}
$$

The thermal stress caused by temperature is expressed as follows [18]:

$$
\sigma=\frac{3 \alpha_{i} E}{1-2 \mu} \Delta T,
$$

where $v_{i}$ is the percentage of the total volume of the various materials, $\alpha_{i}$ is the linear expansion coefficient of a particular material, the volume expansion coefficient is $3 \alpha_{i}, E$ is the elasticity modulus, $\mu$ is the Poisson's ratio, and $\Delta T$ is the change in temperature.

Thermal stress is a vector and its direction points from the region of largest expansion quantities to the region of smallest expansion, as shown in Figure 1.

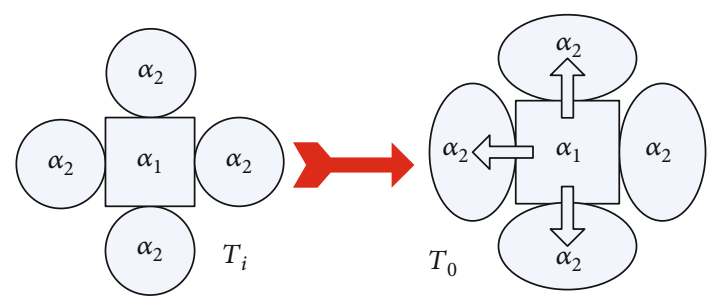

Figure 1: Schematic of the third thermal stress.

The direction of the thermal stress in bulk shale points from the organic matter to the minerals. Assuming that the minerals are fully mixed with the organic matter, the value of the thermal stress in small units can be calculated by the model of Figure 1. The thermal stress is expressed as follows:

$$
\sigma_{T}=\left(\sum v_{i} \alpha_{i}-\alpha_{2}\right) \frac{3 E}{1-2 \mu} \Delta T,
$$

where $\alpha_{i}$ is the linear expansion coefficient of mixture material and $\alpha_{2}$ is the linear expansion coefficient of small materials.

2.2. Balance Differential Equation for the Thermal Stress Field. Temperature change in shale formations can be determined by the depth of the shale. A shale formation at the same depth can be considered to have isothermal conditions because the temperature would not change at the same depth of shale burial. Additionally, shale can be assumed to be an isotropic solid for calculation simplicity [19]. Therefore, a planar coordinate system $(x, z)$ is used to establish differential governing equations for the temperature and stress fields (Figure 2). The temperature $T$ is determined by $T=\eta Z$, where $\eta$ is the geothermal gradient, $\mathrm{K} / 100 \mathrm{~m}$.

The equilibrium, geometric, and physical equations in Cartesian coordinates are as follows [18]:

$$
\begin{gathered}
\left\{\begin{array}{l}
\frac{\partial \sigma_{x}}{\partial x}+\frac{\partial \tau_{z x}}{\partial z}=0, \\
\frac{\partial \tau_{x z}}{\partial x}+\frac{\partial \sigma_{z}}{\partial z}=0,
\end{array}\right. \\
\left\{\begin{array}{l}
\varepsilon_{x}=\frac{\partial u}{\partial x}, \varepsilon_{z}=\frac{\partial w}{\partial z}, \\
\gamma_{x z}=\frac{\partial u}{\partial z}+\frac{\partial w}{\partial x},
\end{array}\right. \\
\left\{\begin{array}{l}
\varepsilon_{x}=\frac{1}{E}\left(\sigma_{x}-\mu \sigma_{z}\right)+\left(\alpha-\alpha_{2}\right) T, \\
\varepsilon_{z}=\frac{1}{E}\left(\sigma_{z}-\mu \sigma_{x}\right)+\left(\alpha-\alpha_{2}\right) T, \\
\gamma_{x z}=\frac{2(1+\mu)}{E} \tau_{x z} .
\end{array}\right.
\end{gathered}
$$

The equilibrium differential equation, using the displacement as the basic unknown function, is obtained through a transformation of Equation (4). 


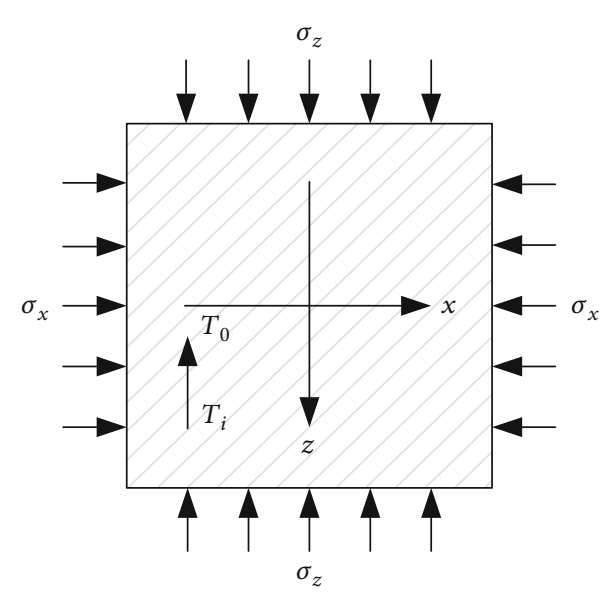

FIGURE 2: The thermal stress analysis diagram.

$$
\left\{\begin{array}{l}
(\lambda+G) \frac{\partial \theta}{\partial x}+G \nabla^{2} u=\frac{\left(\alpha-\alpha_{2}\right) E}{1-2 \mu} \frac{\partial T}{\partial x} \\
(\lambda+G) \frac{\partial \theta}{\partial z}+G \nabla^{2} w=\frac{\left(\alpha-\alpha_{2}\right) E}{1-2 \mu} \frac{\partial T}{\partial z} \\
\theta=\varepsilon_{x}+\varepsilon_{z}=\frac{\partial u}{\partial x}+\frac{\partial w}{\partial z} \\
\lambda=\frac{\mu E}{(1+\mu)(1-2 \mu)}, \\
G=\frac{E}{2(1+\mu)} \\
\nabla^{2}=\frac{\partial^{2}}{\partial x^{2}}+\frac{\partial^{2}}{\partial z^{2}} .
\end{array}\right.
$$

The solution to Equation (5) is obtained by introducing the thermal elastic strain potential function $\Phi(x, z)$ $\left(u^{\prime}=\partial \Phi / \partial x, w^{\prime}=\partial \Phi / \partial z\right)$.

A set of solutions to the equation of state of constant temperature, homogeneous plus, is the general solution of differential equations of equilibrium equations, boundary conditions to obtain simultaneous, displacement solution for determining:

$$
\left\{\begin{array}{l}
u=\frac{f_{x}}{\lambda+2 G} x \\
w=\frac{(1-2 \mu) f_{z}+\left(\alpha-\alpha_{2}\right) E \eta}{(\lambda+2 G)(1-2 \mu)} z^{2}-\frac{1}{3}\left(\alpha-\alpha_{2}\right) \eta \frac{1+\mu}{1-\mu} z^{3}
\end{array}\right.
$$

where $f_{z}$ is the vertical crustal stress, $f_{x}$ is the horizontal stress, and $Z$ is the buried depth.

2.3. Correction Coefficient for Thermal-Hydro-MechanicsCoupled Permeability. The shale strain in the $x$ and $y$ axes (horizontal plane) are the same, because the temperature of the shale is equal at the same depth. So, the shale volume strain $\varepsilon_{v}$ can be formulated as

$$
\varepsilon_{v}=2 \varepsilon_{x}+\varepsilon_{z}=\frac{2(1+\mu)}{(1-\mu)}\left[\frac{(1-2 \mu)\left(f_{x}+T f_{z}\right)}{E}+\left(\alpha-\alpha_{2}\right)\left(T-\frac{T^{2}}{2 \eta}\right)\right]
$$

The empirical formula $K=\sigma \phi^{3} / \Sigma^{2}$ can be used to calculate the permeability of the homogeneous medium under the fluid solid heat coupled conditions, where $\phi$ is the porosity, and $\Sigma$ is the specific surface area, which is the ratio of value of pore surface area and the whole inner volume.

By introducing a modification coefficient $\psi$ to consider the third thermal stress, the equation $K=\psi K_{0}$ can be obtained, where $K_{0}$ is the permeability without considering the third thermal stress.

$$
\left\{\begin{array}{l}
\psi=\frac{K}{K_{0}}=\left(\frac{\phi}{\phi_{0}}\right)^{3}\left(\frac{V}{V_{0}}\right)^{2}\left(\frac{A_{P 0}}{A_{P}}\right)^{2}, \\
\frac{V^{2}}{V_{0}^{2}}=\frac{1}{V_{0}^{2}}\left(V_{0}+\Delta V\right)^{2}=\left(1+\varepsilon_{v}\right)^{2}=1+2 \varepsilon_{v} \\
\frac{A_{P 0}^{2}}{A_{P}^{2}}=\left(\frac{A_{P 0}+\Delta A_{P}-\Delta A_{P}}{A_{P 0}+\Delta A_{P}}\right)^{2}=1-2 \frac{\Delta A_{P}}{A_{P 0}} .
\end{array}\right.
$$

The shale porosity is not affected by the third thermal stress, so $\phi=\phi_{0}$. For the linear elastic strain of a homogeneous medium, an approximation of the internal surface area change is made, which is expressed as $\Delta A_{P} / A_{P 0} \approx(2 / 3) \varepsilon_{v}$.

The above equations are simplified by omitting higher order terms because the linear elastic deformation is small:

$$
\begin{aligned}
K= & K_{0}\left(1+\frac{2 \varepsilon_{v}}{3}\right) \Rightarrow \psi=\frac{K}{K_{0}}=1-\frac{4}{3} \frac{(1+\mu)}{(1-\mu)} \\
& \cdot\left[\left(\alpha-\alpha_{2}\right)\left(\frac{T^{2}}{2 \eta}-T\right)-\frac{(1-2 \mu)\left(f_{x}+T f_{z}\right)}{E}\right] .
\end{aligned}
$$

External factors that affect the correction coefficient of the shale permeability include the temperature difference, geothermal gradient, vertical stress, and horizontal stress. These factors are also related to the medium's elastic modulus, Poisson's ratio, coefficient of expansion, and the mass ratio of its mineral components.

Equation (9) shows that permeability decreases as temperature increases. Permeability decreases largely as a result of increasing the temperature when the difference in the expansion coefficient of shale components is higher and the organic matter content is higher.

2.4. The Permeability Test. It is very difficult to measure shale permeability using conventional steady-state measuring methods because the shale permeability is very low $\left(10-^{3}\right.$ to $\left.10^{-6} \mathrm{mD}\right)$. So, an alternative method such as the transient pulse-decay (TPD) method [20] or the beam-bending method [21] was proposed to measure the shale permeability. In contrast with conventional steady-state permeability test methods, the pulse-decay method does not need to record rock outlet velocity. It has the advantage of high 
measurement accuracy and efficiency, but it has three disadvantages: (1) difficult sample preparation, (2) high sealing of the experimental device, and (3) a requirement for highprecision pressure sensors. Measurement precision with the beam-bending method is higher than with the conventional steady-state permeability test method. A permeability range of 0.009 to $400 \mathrm{nD}$ can be measured by this method, but it also has three disadvantages: (1) complex mathematical models, (2) difficult sample cutting, and (3) small samples with poor representation.

In this work, the transient pulse-decay experiment was used to measure the permeability of shale samples affected by the temperature.

\section{Experiment and Methods}

3.1. Samples. The shale samples used in the laboratory experiments were collected from the lower Silurian Longmaxi Formation in Yibin City, Sichuan Province. The total organic carbon (TOC) content of the samples is $7.88 \%$, and the vitrinite reflectance $\left(R_{0}\right)$ of the samples is $2.85 \%$. These values are in the range of most favorable conditions for the occurrence of shale gas (TOC $\geq 2 \%, 3 \% \geq R_{0} \geq 1 \%$ ) [22]. Shale samples were prepared with $\Phi 25 \mathrm{~mm} \times 50 \mathrm{~mm}$ rock specimen blocks were obtained (Figure 3). Subsequently, the specimens were put into the oven and baked for $24 \mathrm{~h}$ at a temperature of $353 \mathrm{~K}$. Then, the specimens were cooled and sealed in plastic bags.

The mineralogical compositions of shale samples were tested using X-ray diffraction. The X-ray diffraction data were obtained using a Siemens D5000 diffractometer, using $\mathrm{CuK} \alpha$ radiation. The samples were scanned from 2 to $75^{\circ} 2 \theta$, with a step time of $2 \mathrm{~s}$ per $0.02^{\circ}$ step. The results are shown in Table 1.

The triaxial compression strength, elastic modulus, and Poisson's ratio of the samples were tested using MTS815. The results are shown in Table 2 .

3.2. Apparatus. Figure 4 presents a schematic diagram of the permeability measurement apparatus. This apparatus consisted of a temperature control system, an experimental system, a data acquisition system, an auxiliary system, and a triaxial pressure chambers.

The maximum oil field thermostat system can be heated to $473 \mathrm{~K}$, with a temperature control accuracy of $0.1 \mathrm{~K}$. The servo loading system provides a maximum $3000 \mathrm{kN}$ axial load to provide a maximum $200 \mathrm{MPa}$ of confining pressure.

The experimental system consisted of a sample cell, two reference cell $(5 \mathrm{~mL})$, two pressure transducer (Rosemount, American, model 3051, range: 0 to $13.79 \mathrm{MPa}$, accuracy: $8 \mathrm{kPa}$ ), and a pressure difference sensor (Rosemount, American, model 3051, range: 0 to $0.68 \mathrm{MPa}$, accuracy: $0.68 \mathrm{kPa}$ ). The pore pressure is provided by the ISCO pump, with a maximum available gas pressure of about 5000PSI.

3.3. Procedure. Prior to measuring the permeability of shale samples, the apparatus was checked for pressure leaks. The helium was injected into the reference cell. If the values of pressure collected from the pressure transducer decreased less than the accuracy of the pressure transducer $(8 \mathrm{kPa})$ in $24 \mathrm{~h}$, then it was no leaks in the system [23].

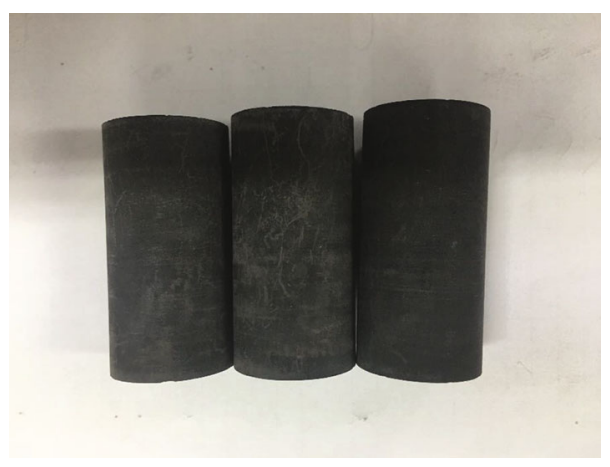

Figure 3: The sample of shale.

TABLE 1: X-ray diffraction results of shale samples.

\begin{tabular}{|c|c|c|c|c|c|c|}
\hline \multicolumn{7}{|c|}{ Mineralogical composition (\%) of shale samples } \\
\hline Quartz & $\begin{array}{l}\text { Potash- } \\
\text { feldspar }\end{array}$ & Plagioclase & Calcite & Dolomite & Pyrites & Clay \\
\hline 53.5 & 1 & 3.1 & 20.3 & 8.7 & 3.6 & 9.8 \\
\hline
\end{tabular}

TABLE 2: Mechanical indexes of shale under uniaxial compression.

\begin{tabular}{lcc}
\hline & Data & Average \\
\hline & 158.88 & \\
Uniaxial strength $(\mathrm{MPa})$ & 154.95 & 158.65 \\
& 160.14 & \\
\hline \multirow{2}{*}{ Elastic modulus $E(\mathrm{GPa})$} & 46.5 & 47.5 \\
& 48.5 & \\
\hline & 47.5 & \\
Poisson's ratio $\mu$ & 0.324 & 0.298 \\
& 0.289 & \\
\hline
\end{tabular}

The sample was subsequently installed in the test cell. The system was allowed to reach thermal equilibrium at the target temperature, based on heating in the oil field, ensuring that any temperature-induced expansion took place. The swelling of the shale in response to increased temperature was considered to have reached its maximum when the strain gauges showed the strain of the sample had plateaued, at which point a vacuum was applied.

We apply a confining pressure of $9 \mathrm{MPa}$, then open the relevant valve of the pulse permeability instruments, and the $\mathrm{N}_{2}$ was used to up to pressure of about $7 \mathrm{MPa}$ to make the net confining pressure on the rock sample to $2 \mathrm{MPa}$. After the pressure of the instrument's upstream chamber, rock sample pores, and downstream chamber, it reaches thermal equilibrium according to the instrument prompts, manually lowering the pressure in the downstream chamber by about $70 \mathrm{kPa}$ to form the initial attenuation pressure pulse.

\section{Results and Discussion}

4.1. Strain Caused by Gas. Kumar et al. [24] measured the permeability of shale samples with helium, methane, and carbon dioxide. They found that the permeability of samples 


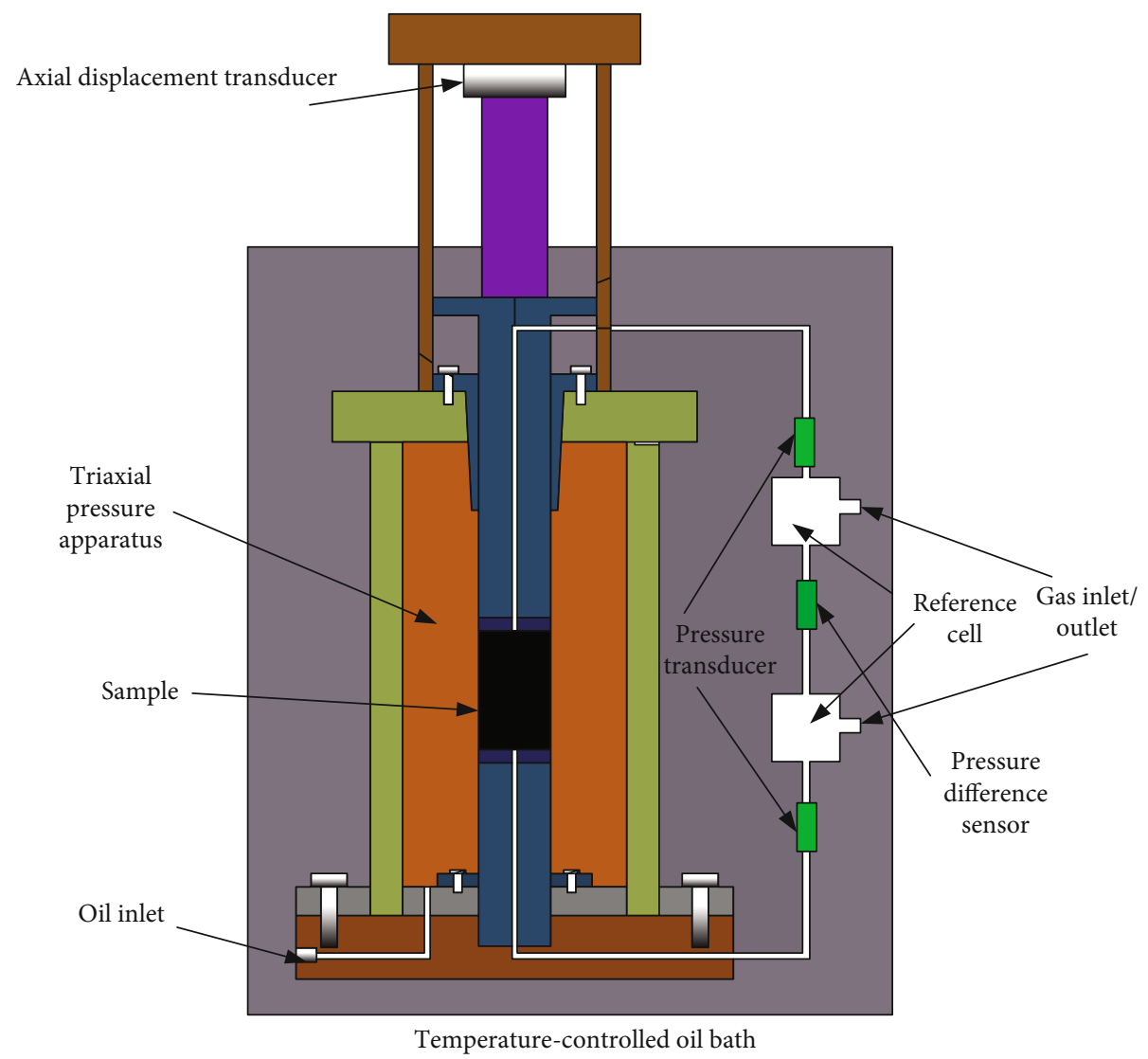

FIGURE 4: The schematic of the experimental apparatus.

decreased by $50 \%$ using carbon dioxide and decreased by $20 \%$ using methane. It is obviously that the strain on the shale caused by gas could affect the permeability of shale. According to the report by Ao et al. [25, 26], there are two effects that induce strain in the sample caused by gas. Gas was slowly adsorbed by the sample, and so the surface potential of the sample was reduced. The volume was also increased with increases in the thickness of the surface layer while free gas penetrated the pores and cracks. In addition, the gas infiltrated into cracks that were greater than or equal to the molecular size of the gas molecules. In this study, the $N_{2}$ was used to measure the permeability. The $N_{2}$ have not obviously adsorption ability, so the adsorption-induced strain on shale could not occur. In addition, the change in effective stress caused by gas pressure does not occur instantaneously. The experiment uses the transient method to measure the permeability, so the test time is very short. Therefore, it is difficult for the gas pressure to produce effective stress changes in this experiment. To sum up, there is no strain caused by the gas.

4.2. Experimental Results of Shale Permeability. The permeability was calculated as

$$
K=\frac{c \mu \phi L^{2} s}{f(a, b)},
$$

where $K$ is the permeability, $\mathrm{mD}$; $c$ is the compressibility of
TABLE 3: The permeability of the sample.

\begin{tabular}{lcccc}
\hline Temperature $(\mathrm{K})$ & 303 & 313 & 323 & 333 \\
\hline Sample 1 & $0.278 \mathrm{uD}$ & $0.268 \mathrm{uD}$ & $0.250 \mathrm{uD}$ & $0.239 \mathrm{uD}$ \\
Sample 2 & $0.256 \mathrm{uD}$ & $0.246 \mathrm{uD}$ & $0.234 \mathrm{uD}$ & $0.223 \mathrm{uD}$ \\
Sample 3 & $0.233 \mathrm{uD}$ & $0.228 \mathrm{uD}$ & $0.216 \mathrm{uD}$ & $0.209 \mathrm{uD}$ \\
\hline
\end{tabular}

the pore fluid of the rock sample, dimensionless; $\mu$ is the gas viscosity, $\mathrm{mPa} \cdot \mathrm{s} ; \phi$ is the porosity of shale, dimensionless; $L$ is the length of shale, $\mathrm{mm} ; s$ is the slope of the pressure difference between the upstream and downstream chambers and time of the pulse permeability tester tested in the single logarithmic graph, dimensionless; $a, b$ is the ratio of the pore volume of the test rock sample to the volume of the upstream and downstream chambers of the pulse permeability meter, respectively; when the value of $a$ is equal to $b$, the amount of $f(a, b)$ is 1.17 . The results of the shale permeability determinations are shown in Table 3.

4.3. Verification of the Permeability Prediction Model. In this work, we have established a model to predict shale permeability. Eight parameters are included in this model, i.e., temperature difference $T$, geothermal gradient $\eta$, vertical stress $f_{z}$, horizontal stress $f_{x}$, the elastic modulus $E$, Poisson's ratio $\mu$, the thermal expansion coefficient $\alpha$, and the proportions of mineral components $v_{i}$. $v_{i}$ was determined based on the 
TABLE 4: Shale component parameter table.

\begin{tabular}{lr}
\hline Parameters & Data \\
\hline Elastic modulus $E(\mathrm{GPa})$ & 47.5 \\
Poisson's ratio $\mu$ & 0.29 \\
Geothermal gradient $\eta\left(\mathrm{K} \cdot \mathrm{m}^{-1}\right)$ & 0.03 \\
Axial stress $f_{z}(\mathrm{MPa})$ & 30.0 \\
Horizontal stress $f_{x}(\mathrm{MPa})$ & 20.0 \\
The linear expansion coefficient of organic matter $\left(10^{-6} \cdot \mathrm{K}^{-1}\right)$ & 30.0 \\
The linear expansion coefficient of minerals $\left(10^{-6} \cdot \mathrm{K}^{-1}\right)$ & 3.0 \\
\hline
\end{tabular}

TABLE 5: Correction factor tables.

\begin{tabular}{lccc}
\hline $\begin{array}{l}\text { Temperature } \\
\text { difference }(\mathrm{K})\end{array}$ & $\begin{array}{c}\text { Correction } \\
\text { factor }\end{array}$ & $\begin{array}{c}\text { Temperature } \\
\text { difference }(\mathrm{K})\end{array}$ & $\begin{array}{c}\text { Correction } \\
\text { factor }\end{array}$ \\
\hline 5 & 0.9995 & 25 & 0.9410 \\
10 & 0.9932 & 30 & 0.9125 \\
15 & 0.9813 & 35 & 0.8785 \\
20 & 0.9639 & & \\
\hline
\end{tabular}

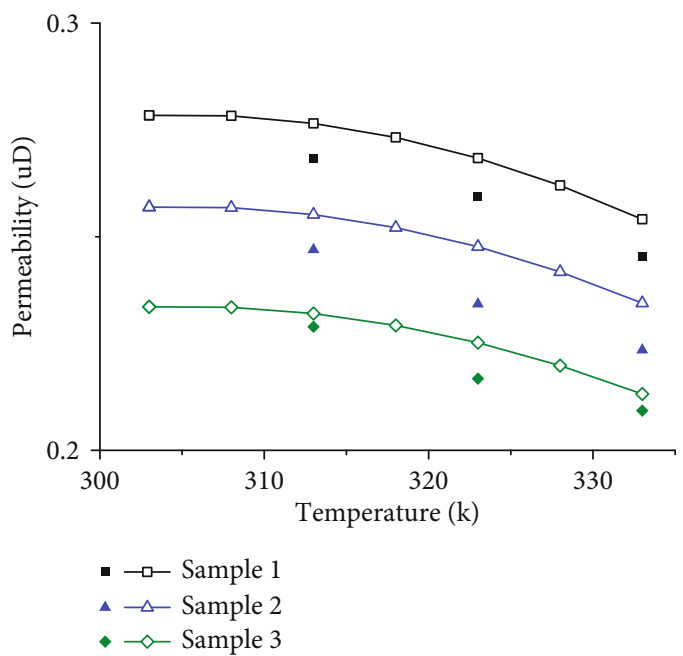

FIGURE 5: The relationship of temperature and permeability; the scatters were experiment data, while the curve was the model data.

results reported by Rahman [27], who pointed out that the TOC of shale is about $10 \%$, whereas the mineral content of shale is about $90 \%$. The parameters used in the model are shown in Table 4.

The correction coefficient for the temperature difference was calculated using equation (9) and reported in Table 5.

To eliminate the effect of the second thermal stress on the results, and based on the experimental conditions, the permeability at $303 \mathrm{~K}$ was considered the initial permeability of the model. Therefore, only the third thermal stress will affect the results. Figure 5 presents the model representations for the shale permeability.

Figure 5 compares the experimental and modeled shale permeability values. Note in the figure that the permeability predicted by the model is in good agreement with the mea- sured data. In addition, the permeability was found to decrease as temperature increased. The model and experimental values were closer at lower permeabilities. This indicates that for a mixture of a hypotonic medium with a low permeability, the effect of the third thermal stress is higher as a result of the reduction in the permeability.

\section{Conclusions}

This paper presents a theoretical model to describe the impacts of temperature on shale permeability under the third thermal stress condition. This model was built on the principles of thermodynamics and mechanics of elasticity. All parameters included in this model have physical meanings, which provide a predictive basis for constraining the shale permeability.

The main constituents in the shale sample are minerals and organic matter. A shale sample will produce uneven swelling because the thermal expansion coefficients of the minerals and organic matters are different as a result of the effects of temperature change. The third thermal stress is caused by uneven swelling. Furthermore, shale permeability will change under the effects of matrix swelling, which is caused by both ground and thermal stresses. We have also modified the formula for the correction coefficient of the shale permeability. The shale permeability predicted by the model coincides with the experimentally measured permeability, which decreases as the temperature rises. Additionally, the accuracy of the permeability corrections was found to be higher when the permeability was reduced. The shale permeability decreased more rapidly when the temperature increased, particularly while the difference in the shale component expansion coefficients was larger and the organic matter content was higher.

\section{Data Availability}

The data used to support the findings of this study are available from the corresponding author upon request.

\section{Conflicts of Interest}

The authors declare that they have no conflicts of interest. 


\section{Acknowledgments}

This study was funded by the National Key Basic Research Program of China (No. 2014CB239206), the Natural Science Foundation of Chongqing (Nos. cstc2019jcyj-msxmX0507 and cstc2019jcyj-zdxmX0024), and the Scientific and Technological Research Program of Chongqing Municipal Education Commission (KJQN20200).

\section{References}

[1] R. Heller, J. Vermylen, and M. Zoback, "Experimental investigation of matrix permeability of gas shales," AAPG Bulletin, vol. 95, no. 5, pp. 975-995, 2014.

[2] F. Javadpour, H. Singh, A. Rabbani, M. Babaei, and S. Enayati, "Gas flow models of shale: a review," Energy and Fuels, vol. 35, no. 4, pp. 2999-3010, 2021.

[3] O. Kwon, A. K. Kronenberg, A. F. Gangi, and B. Johnson, "Permeability of Wilcox shale and its effective pressure law," Journal of Geophysical Research: Solid Earth, vol. 106, no. B9, pp. 19339-19353, 2001.

[4] G. R. L. Chalmers, D. J. K. Ross, and R. M. Bustin, "Geological controls on matrix permeability of Devonian Gas Shales in the Horn River and Liard basins, northeastern British Columbia, Canada," International Journal of Coal Geology, vol. 103, pp. 120-131, 2012.

[5] M. Firouzi, K. Alnoaimi, A. Kovscek, and J. Wilcox, "Klinkenberg effect on predicting and measuring helium permeability in gas shales," International Journal of Coal Geology, vol. 123, pp. 62-68, 2014.

[6] Z. Song, Y. Wang, H. Konietzky, and X. Cai, "Mechanical behavior of marble exposed to freeze-thaw-fatigue loading," International Journal of Rock Mechanics and Mining Sciences, vol. 138, article 104648, 2021.

[7] X. Cai, Z. Zhou, L. Tan, H. Zang, and Z. Song, "Fracture behavior and damage mechanisms of sandstone subjected to wetting-drying cycles," Engineering Fracture Mechanics, vol. 234, p. 107109, 2020.

[8] C. Y. Fan and Z. L. Wang, "Geological factors and process in enrichment and high production of shale gas," Petroleum Geology \& Experiment, vol. 32, no. 5, pp. 465-469, 2010.

[9] R. Pan and X. Huang, "Shale gas and its exploration prospects in China," China Petroleum Exploration, vol. 3, pp. 1-7, 2009.

[10] J. Y. Xu and A. J. Wu, "The development status of shale gas in the world and its exploration prospect in China," Pecial Oil and Gas Reservoirs, vol. 17, no. 5, pp. 1-9, 2010.

[11] S. Zhang, M. S. Paterson, and S. F. Cox, "Microcrack growth and healing in deformed calcite aggregates," Tectonophysics, vol. 335, no. 1-2, pp. 17-36, 2001.

[12] Z. Q. LI and X. Xian, "Study on experiment of coal permeability with temperature and stress changing," Journal of Liaoning Technical University, vol. 28, pp. 156-159, 2009.

[13] B. Liang, H. M. Gao, and Y. M. Lan, "Theoretical analysis and experimental study on relation between rock permeability and temperature," Chinese Journal of Rock Mechanics and Engineering, vol. 24, no. 12, pp. 2009-2012, 2005.

[14] Z. Y. Feng, Y. S. Zhao, Z. Y. Wan, G. W. Li, C. Wang, and Y. Zhang, "Law of permeability in the process of anthracite deformation with thermo-mechanical coupling," Journal of China Coal Society, vol. 35, pp. 86-90, 2010.
[15] W. Li, B. Huang, and Z. Bi, The Thermal Stress Theory and Application, China Electric Power Press, Beijing, China, 2004.

[16] H. G. Xu, Z. H. Shui, R. Zhang, W. Chen, and J. J. Zeng, "Effect of metakaolin on thermal expansion of hardened cement paste," Bulletin Of The Chinese Ceramic Society, vol. 30, no. 2, pp. 278-283, 2011.

[17] B. B. Zhang, Effect of Expansion Coefficient on the Quanlitry of the Optical Glass, Changchun University of Science and Technology, Changchun, China, 2005.

[18] J. L. Wu, Theory of Elastic Mechanics, Higher Education Press, Beijing, China, 2001.

[19] R. Gautam and R. C. Wong, "Transversely isotropic stiffness parameters and their measurement in Colorado shale," Canadian Geotechnical Journal, vol. 43, no. 12, pp. 1290-1305, 2006.

[20] A. Sakhaee-Pour and S. Bryant, "Gas permeability of shale," SPE Reservoir Evaluation \& Engineering, vol. 15, no. 4, pp. 401-409, 2012.

[21] J. Zhang and G. W. Scherer, "Permeability of shale by the beam-bending method," International Journal of Rock Mechanics and Mining Sciences, vol. 53, pp. 179-191, 2012.

[22] W. D. Zhang, M. Guo, and Z. X. Jiang, "Parameters and method for shale gas reservoir evaluation," Natural Gas Geoscience, vol. 22, no. 6, pp. 1093-1099, 2011.

[23] C. Pongtorn, A. M. Sayeed, and L. Robert, "High-pressure adsorption of gases on shales: measurements and modeling," International Journal of Coal Geology, vol. 95, pp. 34-46, 2012.

[24] H. Kumar, D. Elsworth, C. J. Marone, and J. Mathews, "Permeability evolution of shale and coal under differential sorption of $\mathrm{He}, \mathrm{CH} 4$ And CO2," Presented at the 2010 Fall Meeting of the American Geophysical Union, 2010.

[25] X. Ao, Z. Qi, Z. Xiang, Z. Li, H. Qu, and Z. Wang, "Swelling of shales by supercritical carbon dioxide and its relationship to sorption," ACS Omega, vol. 5, no. 31, pp. 19606-19614, 2020.

[26] X. Ao, B. Wang, H. Qu, Z. Xiang, and Z. Luo, "Swelling of shales with slickwater in carbon dioxide," Energy \& Fuels, vol. 35, no. 6, pp. 5122-5129, 2021.

[27] W. M. Rahman, “Use classified kerogen," Journal of Petroleum Geology, vol. 8, no. 2, pp. 167-176, 1996. 